MEASURING GLOBAL AND REgional TRADE INTEGRATION IN TERMS OF CONCENTRATION OF ACCESS.

\author{
T.Huw Edwards
}

CSGR Working Paper Series 206/06

May 2006 


\title{
Measuring Global and Regional Trade Integration in terms of Concentration of Access.
}

T.Huw Edwards, Dept of Economics, Loughborough University and Centre for the Study of Globalisation and Regionalisation, Warwick UK.

May, 2006.

\begin{abstract}
:
I apply concentration measures from the inequality literature - the Lorenz curve and Gini coefficient - to the measurement of global and regional integration, and show that these can be derived from the theoretical gravity model in the presence of unequal costs of access for firms from different locations to a particular market.
\end{abstract}

Overall, comparing 9 economies, I find that the USA is the most globalised on these measures, and India and China are the least globalised. The smaller EU economies, which are very open on standard measures, should probably be viewed as regionalised rather than globalised.

Keywords:

Globalisation, Regional Integration, Trade, Statistics

JEL classifications: F10, F 15, C49

\section{Contact Details:}

Department of Economics, Loughborough University, Loughborough,

Leics

LE11 3TU,

United Kingdom.

Tel (44)(0)1509-2122717.

T.H.Edwards@lboro.ac.uk.

Thanks particularly to Helena Marques at Loughborough for comments and suggestions. Any errors are my own. 


\section{Introduction}

To date, there is no real consensus on how global and regional integration should actually be measured. While a reading of the press might give the idea that countries are rapidly losing their national identities, many data-based studies indicate that, in fact, national boundaries still play an enormous part in economic life. ${ }^{1}$ These papers have their critics $^{2}$, and international trade is, in any case, only one aspect of integration, but nevertheless, they do serve to indicate the need to develop simple and easily-interpreted measures to quantify the processes at work.

This paper suggests a possible approach: the application of measures from the economic literature on inequality or concentration - the Gini coefficient and Lorenz curve - to trade data. This produces simple, summary statistics, based on techniques familiar to most economists, which can be applied to a variety of countries and industries, which can deal with the thorny problem of country size and which can be adapted to provide a method for distinguishing between proper global integration and regional-based integration. In addition, these are linked very closely both to the entropy-based measures of industrial concentration used in the geographical literature and to the theoretical gravity model, with its roots in the 'love of variety' approach of the New Trade Theory. ${ }^{3}$

To understand the conceptual link between concentration/inequality measures of integration and the variety-based approach, I suggest it helps to view global or regional integration as issues of market access. Based on the assumption that consumers like to spread consumption over a wide number of varieties of a good, then a concentrated trade pattern will only be observed when economic, political, geographical and social factors intervene to make market access unequal across producers from different countries. From this perspective, a market becomes more globalised as producers worldwide gain more equal access to that market.

\footnotetext{
${ }^{1}$ For example, McCallum's classic (1995) study of trade patterns between Canadian provinces and US states, which indicated that trade between Canadian provinces exceeds that with neighbouring US states by a factor of over 20, once correction is made for size and distance, or Trefler's (1995) 'missing trade' paper, which indicated a high degree of 'home bias' in trading patterns around the globe.

${ }^{2}$ See, for example, Hillberry, 1999, or Anderson and Van Wincoop, 2003.

${ }^{3}$ See, e.g. Dixit and Stiglitz, 1977, Krugman, 1979.
} 
If increasing access is only concentrated within a region of the world, then the market should be viewed as regionalised. ${ }^{4}$

In section 2, I discuss existing approaches to the measurement of globalisation and regionalisation. In section 3, I outline in principle the approach of this paper. Section 4 shows the algebraic development of this method. Section 5 relates it to the theoretical gravity model and to entropy measures. In section 6 , I carry out some specimen calculations comparing the global and regional integration of a small sample of countries across a range of industries, and compare the results with existing indices of globalisation.

\section{The Measurement of Globalisation and Regionalisation}

There is no single agreed set of measures of global and regional integration. Measures of globalisation range from the purely trade-based measures to more ambitious composite indices, which take account of international investment, cultural and social factors, political factors (e.g. membership of international political bodies) and the like. This latter work was pioneered by A.T.Kearney for Foreign Policy magazine, and has since been joined by the Warwick Globalisation Index. ${ }^{5}$ These indices provide useful insight into how various aspects of global integration are proceeding over time, and 'league tables' of how globalised various countries are according to the various measures. According to the Warwick index, economic globalisation is led by Ireland, Belgium, Hong Kong and Singapore, while the USA is not in the top 20. By contrast, while the smaller open countries are still high in the list for overall globalisation, the UK is ranked 6th (as against 15th for overall globalisation) and the USA 7th, while Russia appears at 19th for overall globalisation (again it is much lower on economic globalisation). This immediately hints at an important issue: the economic globalisation measures appear to be giving much higher weighting to small, open economies (such as Ireland, Belgium or Hong Kong) than to larger economies - even despite quite sophisticated statistical attempts to correct for country size.

\footnotetext{
${ }^{4}$ Note that this paper uses a descriptive statistical approach to measuring globalisation. As such, it does not directly address the question of whether a market is 'unglobalised' due to trade barriers, as opposed to social/cultural barriers or geographical isolation. In this regard, the conceptual approach is rather different to some studies - e.g. Riezman et al (2005) - which interpret globalisation as meaning the absence of policy barriers only.

${ }^{5}$ See Lockwood, 2004, and Lockwood and Redoano, 2005.
} 
The issue of country size is even more marked when we look at standard economic measures of globalisation. For example, openness is often measured in terms of the ratio (Exports + Imports)/GDP, or maybe just Exports/GDP. Needless to say, most small economies are far more open on most measures than are large economies. Often this is for obvious reasons: for example, a consumer in Luxembourg has no alternative to buying a foreign-made automobile. However, even for countries which are not tiny, the variation in consumers' tastes (or, alternatively, individual consumers' tastes for variety) mean that some purchases will be made abroad, and the proportion of demand which will be met by imports is generally higher the smaller the country is, due to there being more variety of products available abroad compared to at home. This will be discussed in the next section.

Gravity models form an alternative, more complex means of assessing trade integration. In this case (see, e.g. Deardorff, 1983) trade flows are regressed on country GDP, income per capita and distance between each pair of countries. This model (which can be theoretically linked to the 'love of variety' approach ${ }^{6}$ ) can provide a means of providing an estimate of how open or closed the economy is after taking account of size and remoteness - the most significant terms which appear in a set of gravity equations are probably those on the various country and regional dummy variables, which show how far countries' trade patterns differ from what size and distance alone would indicate. Nevertheless, the gravity models do not provide a single punchline figure for easy cross-country comparisons. There is also a potential comment that, while correcting for the effects of remoteness may provide an improved estimate of the scale of man-made barriers to trade (tariffs, quotas, regulatory and cultural barriers), natural remoteness is a genuine factor in impeding globalisation of some regions in particular: if we remove this effect we will be overestimating the real progression of global trade and influence into remoter parts of the planet.

Beyond this, there is the need to integrate more closely our analysis of global and regional patterns of trade. This is particularly important in the comparison of the United States with the European Union economies. This is illustrated in the comparisons between the UK and USA in Table 1, below. This compares the market share taken by domestic producers and by regional producers for 9 product categories in the United Kingdom

\footnotetext{
${ }^{6}$ See Bergstrand (1989).
} 
and United States. In the case of the UK, 'regional producers' is taken to mean the European Union states, the 2005 accession states (whose accession process had already begun following the 1995 Europe Agreements) and the other states of the European Economic Area. For the USA, 'regional producers' includes Mexico and Canada.

Table 1: share of domestic producers and regional producers in total sales, United Kingdom and United States, 2001. (Data derived from GTAP version 6).

\begin{tabular}{||lcll||}
\hline \hline DOMESTIC Producers & UK & USA & USA-UK \\
\hline Food crops & 47.3 & 84.1 & 36.8 \\
Meat and dairy & 90.8 & 96.0 & 5.2 \\
Minerals & 67.2 & 58.5 & -8.6 \\
Food products & 83.4 & 95.3 & 9.0 \\
Light manufactures & 59.1 & 75.3 & 16.2 \\
Heavy manufactures & 60.0 & 79.4 & 19.4 \\
Textiles & 53.9 & 70.7 & 16.8 \\
Metals & 73.3 & 88.7 & 15.4 \\
Services & 95.6 & 98.6 & 3.0 \\
\hline \hline REGIONAL producers & & & \\
\hline Food crops & 73.4 & 89.4 & 16.0 \\
Meat and dairy & 95.1 & 98.1 & 2.9 \\
Minerals & 85.5 & 71.6 & -13.9 \\
Food products & 96.3 & 96.7 & 0.4 \\
Light manufactures & 79.4 & 81.9 & 2.5 \\
Heavy manufactures & 86.3 & 86.3 & -0.2 \\
Textiles & 73.1 & 74.8 & 1.6 \\
Metals & 86.5 & 92.4 & 5.9 \\
Services & 98.7 & 1.2 \\
\hline \hline A & & & \\
\hline
\end{tabular}

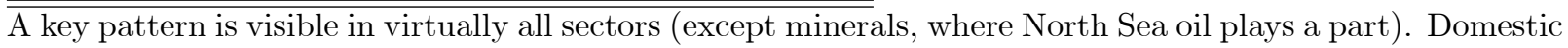


producers take a significantly higher share of the market in the USA than in the UK. On standard measures of trade openness, this would imply that the USA is less open than the UK. However, when regional producers are included, there is very little difference in most sectors except food crops (both countries rely between $70 \%$ and $98 \%$ on domestic or regional producers across all sectors). This indicates that, while the UK is more open to imports than the USA, this only applies to imports from the EU region. In terms of openness to the rest of the World, Europe and North America do not differ vastly.

A central aim of this study is therefore to develop a set of measures of trade openness which take account of differences in country size, and which can distinguish between openness to a region and openness to global trade.

\section{Methodology}

This paper concentrates solely upon trade-based measures of global and regional integration. It is therefore less ambitious in its scope than the Foreign Policy or Warwick Globalisation Indices, not taking account of foreign direct investment, cultural ties, political ties and so on. The aim of concentrating on trade-based measures is to derive a simpler set of measures, but with a more cohesive theoretical backing, which is clearly harder when one tries to take account of diverse aspects of international integration.

The central starting-point is a notion of economic integration based upon the degree of equality of access producers in any market have to a particular market, as inferred from the concentration of trade. In particular:

Definition 1 a country C's market is said to be more highly integrated with region $R$, the more equal is the inferred degree of access producers across $R$ have to $C$ 's market.

Definition 2 a country C's market is said to be more highly globally integrated the more equal is the inferred degree of access producers anywhere in the World have to C's market.

There is a well-established economic literature on measurement of inequality (see, for example, Atkinson, 1983). Amongst other measures are the Lorenz curve and the related Gini Coefficient. The Lorenz curve 
of household income distribution, for example, is based upon ranking all households according to income. The horizontal axis of the graph displays the cumulative number of households, starting with the poorest, while the vertical axis shows cumulative income. As we move rightwards towards wealthier individuals, the curve gets steeper. The Gini coefficient is often interpreted as the ratio of the area between the Lorenz curve and the straight line linking its two endpoints to the total area under the straight line. A Gini coefficient of zero indicates the Lorenz curve itself is straight, and there is perfect equality, while a Gini coefficient of one indicates complete inequality, with one household earning all the income. Typical coefficients for income distribution in advanced countries are between 0.25 and 0.45 (see World Bank).

When it comes to applying this approach to market access, we need to decide what variable we are using for the horizontal axis. We could plot cumulative sales of, say, food products to the UK by all countries ranking them according to sales in the UK per head of their own population. ${ }^{7}$ However, it may be better to start simply by comparing production in different countries, and plotting total sales in the UK against total output in a given sector by each country (ranked by share of production sold to the UK). This can be seen as a market access equality measure, based upon the rather heroic assumption that all producers are of the same size (so that countries with a higher level of observed output have a larger number of producers). This assumption is essentially similar to those underlying the theoretical (variety-based) gravity approach (see Anderson and van Wincoop 2003 or Bergstrand, 1989).

Figure 1, below, shows a Lorenz curve drawn in this way for sales of food crops in the UK in 2001. We can see that the Lorenz curve lies well below the straight line for most of its length, and in fact the associated Gini coefficient is 0.82 . On the basis of this high Gini coefficient, we can say that the UK buys its food crops very unevenly from different parts of the World, a conclusion which is perhaps unsurprising given the combination of transport costs and trade barriers (associated with the Common Agricultural Policy) in this sector.

There are a number of appealing features about this approach. First, the Gini coefficient is calculated from a sum-of-squares formula (when it is not calculated directly from the Lorenz curve). This fits in well with

\footnotetext{
${ }^{7}$ This approach - with its potentially more radical interpretation of globalisation - is perhaps also worthy of investigation. Essentially, it would imply that the World economy can never be fully globalised until there is a high degree of equality in incomes and productivity across countries.
} 
Lorenz Curves for food crop sales in UK, 2001.

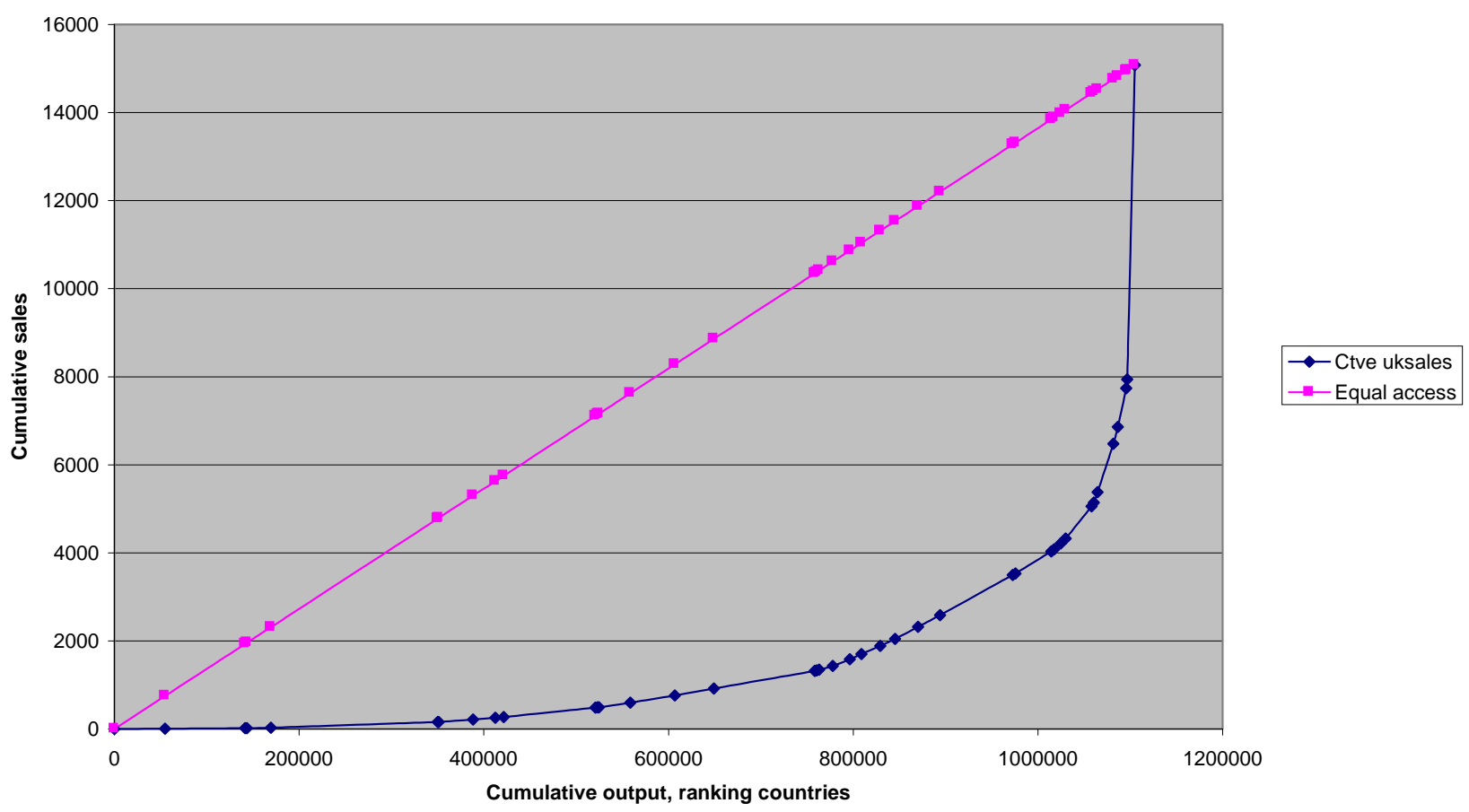

entropy-based measures used elsewhere in calculating, say, regional clustering of industrial production (see Krugman, 1991). Secondly, like most sum-of-squares approaches, the Gini coefficients can be decomposed into within-sample and between-sample coefficients, so that it is not difficult to decompose a headline figure for inequality across countries in terms of market access to a particular country (say, the UK) into differences in market access between regions (say, Europe and the Rest of the World) and differences within those regions. In practice, this means that, as well as calculating a Global-based Gini coefficient, we can calculate a regionalbased Gini coefficient (splitting suppliers into European producers and the rest). If a high degree of the inequality, as measured by the Lorenz curve in Figure 1 is in fact caused by a difference between European suppliers and non-European suppliers, then the regional-based Gini coefficient will be much lower than the Global-based Gini coefficient. This is explained in more technical terms in the next section. 


\section{Application to measurement of globalisation and regionalisation}

I intend to calculate these measures on a sector-by-sector basis, to tell both which countries and which sectors are more integrated globally and/or regionally. I denote the importing country as $h$, but for most purposes I drop subscripts identifying the importing country, for simplicity. We are therefore comparing sales of goods in a particular class from country $c$ to country $h$, which I denote by $x_{c}$. Note that $c$ includes country $h$, so that $x_{h}$ is home sales by producers in $h$. There are $C$ countries in total, so $c=1 \ldots C$. Country $d$ denominates another country in the set $c$.

I am comparing $c$ 's sales in country $h\left(x_{c}\right)$ with the overall level of output in exporting country $c, y_{c}$.

\subsection{Globalisation}

The Gini coefficient for inequality between individuals can be calculated by the formula

$$
G=\left[\sum_{i} \sum_{j} \sqrt{\left(m_{i}-m_{j}\right)^{2}}\right] /\left(2 n^{2} \mu\right)
$$

where $m_{i}$ denotes income of individual $i, m_{j}$ is income of individual $j, n$ is the number of individuals and

$$
\mu=\sum_{i} m_{i} / n
$$

This formula needs adapting for trade between countries, as they vary significantly in size. I am assuming there are $C$ countries $(c=1 \ldots C)$, where importing country $h$ is a member of this set, and that the level of output in the industry concerned within country c is $y_{c}$. Imports into country $h$ from country $c$ are denoted $x_{c}$. I will assume (rather courageously) that all firms within country $c$ are identical, of size 1 unit. Consequently, exports per firm are $x_{c} / y_{c}$, and there are $y_{c}$ firms in country $c$. Total world output (which equals the number of firms) is

$$
Y=\sum_{c} y_{c}
$$


Mean sales in the UK per firm worldwide are

$$
M=\sum_{c} x_{c} / Y
$$

Total world exports to the UK

$$
X=\sum_{c} x_{c}
$$

We therefore have a Gini coefficient of

$$
\begin{aligned}
G & =\left[\sum_{c} \sum_{d} y_{c} y_{d} \sqrt{\left(\left(x_{c} / y_{c}\right)-\left(x_{d} / y_{d}\right)\right)^{2}}\right] /\left(2 Y^{2} \sum_{c} x_{c} / Y\right) \\
& =\left[\sum_{c} \sum_{d} y_{c} y_{d} \sqrt{\left(\left(x_{c} / y_{c}\right)-\left(x_{d} / y_{d}\right)\right)^{2}}\right] /(2 Y X) .
\end{aligned}
$$

I will denote this Gini coefficient $G G$ (the 'globalisation Gini'). If Britain's consumption within the industry is 'totally globalised' we would expect $G G=0 .{ }^{8}$

\subsection{Home bias and regionalisation}

An interesting question is what proportion of the inequality captured in the globalisation Gini coefficient is in fact explained by either a) 'home bias' (the difference in market access between the home nation, $H$, and the rest of the World, $N$ ) or b) 'regionalisation': the difference between one subset of countries, $c \subset R$, the 'region' (for example the European Union), and the Rest of the World, $c \subset N$. I suggest that the globalisation Gini can effectively be decomposed by showing how closely the overall Gini coefficient corresponds to those based upon either a home country/other countries breakdown or a home country/region/rest of the World breakdown. I consider these.

\footnotetext{
${ }^{8}$ Note, Ogwang (2000) has also suggested a procedure for estimating Gini coefficients by a weighted least squares procedure using ranked data, and of deriving their standard errors. This is, however, based upon single observations (whereas we are effectively counting a country with output $y_{c}$ as having $y_{c}$ observations), so the procedure would require some modification. Nevertheless, there is an interesting avenue of research linking these coefficients to empirical trade models (of the theory-based gravity kind). In particular, it may give a possible avenue of approach using gravity coefficients to decompose the 'causes' of differences in global or regional integration across countries (in terms of remoteness, language and cultural ties, trade bloc membership, protection etc.).
} 
Home bias There is strong evidence (McCallum, 1995, Trefler, 1995), that considerable 'home bias' is present in gravity models of trade, and this applies even within regional trade blocs. ${ }^{9}$ This would indicate that we would expect a split between $H$ and $N$ to provide a high Gini coefficient, so that home producers are considerably favoured compared to foreigners.

One approach to measuring this is simply to take total output and total sales to the importing country from regions $H$ and $N$ - which I here denote as $x_{h}, x_{n}, y_{h}$ and $y_{n}$ respectively. Again, note that

$$
\begin{aligned}
& x_{h}+x_{n}=X, \\
& y_{h}+y_{n}=Y .
\end{aligned}
$$

We can therefore define a 'Home-Based Gini' (HBG) as

$$
H B G=\left[y_{h} y_{n} \sqrt{\left(\left(x_{h} / y_{h}\right)-\left(x_{n} / y_{n}\right)\right)^{2}}\right] /(2 Y X) .
$$

This method is essentially approximating the Lorenz curve with two straight-line sections, one for the home country, $H$, which almost certainly lies at the right end of the horizontal axis, and one for the rest of the World, $N^{\prime}$ (defined as excluding $H$, but including $R$, so that $N^{\prime}=R \cap N$ ). The approximation will work better the more equal are the ratios of sales/production for each of the countries within $H$ and each of the countries within the Rest of the World.

The $H B G$ measure should be more closely related to standard openness measures, ${ }^{10}$ though with a correction for country size. It would therefore not be surprising if $H B G$ measures corresponded closely to existing league tables of economic globalisation.

\footnotetext{
${ }^{9}$ Brenton et al (2001).

${ }^{10} \mathrm{Such}$ as (exports + imports)/GDP.
} 


\subsubsection{Regional bias}

As an intermediate measure between $H B G$ and $G G$, it is also worth considering a 'Home-and-Region-Based Gini' $(H R B G)$. This splits the World into three blocs: the Home country, $H$, the rest of the Region, $R$, within which $H$ is situated and the Rest of the World, $N$. If $H R B G$ is substantially higher than $H B G$, then it indicates that there is a significant difference in access to $H$ 's market for firms in $R$ compared to those in $N$. If $H R B G$ is also close to $G G$, then we can essentially say that the country's trade patterns are dominated by regionalisation. By contrast, if $G G$ is still considerably greater than $H R G B$, then this suggests that there are considerable concentration features in the trade pattern which are not captured by simply the three-way split.

\section{Relationship to the existing trade theories and measures}

\subsection{The 'love of variety' model and theoretical gravity model}

The 'love of variety' model (Dixit and Stiglitz, 1977) is widely applied to explain the prevalence of intra-industry trade, particularly in differentiated goods among advanced economies. In each country, a 'representative' consumer has a utility function characterised by a constant elasticity of substitution among different goods varieties. Taking one version of this model (Edwards, 2005), we can represent utility in country $c c$ by

$$
U_{c c}=\left[\sum_{c} \sum_{g \in c}\left(\left(1-\phi_{c, c c}\right) Q_{g, c c}\right)^{(\sigma-1) / \sigma}\right]^{\sigma /(\sigma-1)}
$$

where $\sigma$ is the elasticity of substitution between goods varieties, $Q_{g, c c}$ is the volume of goods produced by $g$ consumed in $c c$ and $\phi_{c, c c}$ is an iceberg cost reducing by a fixed proportion the usable value of all goods from country $c$ consumed in $c c$. With a Dixit-Stiglitz framework, the assumed value for $\sigma$ must exceed unity, with the corresponding substitution parameter, $\rho=(\sigma-1) / \sigma$, lying between 0 and 1 .

Assuming the price of producing goods in country $c$ is $P_{c}$, the turnover of a typical firm is $T_{c}$, the value of 
exports from $c$ to $c c$ is $x_{c, c c}$, total demand in $c c$ is $X_{c c}$ and total output in $c$ is $y_{c}$, then we can write

$$
x_{c, c c}=\left(1-\phi_{c, c c}\right)^{(\sigma-1)} y_{c} X_{c c} T_{c}^{-1} P_{c}^{1-\sigma} \pi_{c c}^{\sigma-1},
$$

where $\pi_{c c}$ is the CES aggregate price of utility in country $c c$. On the simplifying assumptions that costs and firm scale are equal across countries, $T_{C}=\bar{T}, P_{c}=P$, taking logs, and assuming

$$
\ln \left(1-\phi_{c, c c}\right)=a-b \ln d_{c, c c}+\varepsilon_{c, c c}
$$

where $d_{c, c c}$ is distance, it is straightforward to show that this is equivalent to a theoretical gravity model, with coefficients on importing country demand and exporting country equal to unity.

Now consider a situation where $P_{c}=1$ and $T_{c}=1$ for all $c$, so that the love of variety and trade costs (including transport, tariffs and non-tariff barriers) are the sole factors determining trade. In this case,

$$
x_{c, c c}=\left(1-\phi_{c, c c}\right)^{(\sigma-1)} y_{c} X_{c c} \pi_{c c}^{\sigma-1}
$$

and since

$$
\sum_{c} x_{c, c c}=X_{c c}
$$

it follows that

$$
X_{c c}=\left(1-\phi_{c, c c}\right)^{(\sigma-1)} y_{c} X_{c c} \pi_{c c}^{\sigma-1}
$$

By deriving an expression for $\pi_{c c}$ and substituting in for it, we can show that the Global Gini for country $c c$, $G G_{c c}$, is a weighted measure of the relative variability of trade costs:

$$
G G_{c c}=\left(\sum_{c} \sum_{d} y_{c} y_{d} \sqrt{\left(\left(1-\phi_{c, c c}\right)^{(\sigma-1)}-\left(1-\phi_{d, c c}\right)^{(\sigma-1)}\right)^{2}}\right)\left(Y /\left(\sum_{c}\left(1-\phi_{c, c c}\right)^{(\sigma-1)} y_{c}\right)\right) .
$$

The derivation of (13) is shown in Appendix 2. 


\subsection{The Krugman specialisation index}

Before looking at some illustrative calculations based upon the Gini approach, it is worth noting that a closelyrelated approach is already in use for measuring the spatial specialisation in a particular industry: notably the Krugman concentration index. ${ }^{11}$ This takes the form

$$
K_{c d}=\sum_{z} \sqrt{s_{z c}-s_{z d}}
$$

where $K$ is the Krugman index, $c$ and $d$ are the two regions and $s_{z c}$ and $s_{z d}$ represent the shares of industry $z$ in total employment in each region respectively. A comparison with (1) shows this is algebraically very close to a Gini measure.

Gini coefficients per se are also used for measuring regional specialisation. ${ }^{12}$

\section{Some illustrative calculations}

In this section, I carry out some specimen calculations of these Gini coefficients using cross-sectional trade data for 2001 drawn from the GTAP version 6 database. ${ }^{13}$ The calculations are based upon a somewhat aggregated version of the GTAP database, with 9 product categories ${ }^{14}$ and 39 regions. ${ }^{15}$ The intention is to give some illustrative calculations, and in particular I have concentrated upon access into 8 markets: The UK, Belgium, Ireland (two small EU countries which figure top on the Warwick 'trade-based globalisation' rankings), Canada

\footnotetext{
${ }^{11}$ See Krugman, 1991. A clear explanation is also available online from the German Centre for European Integration Studies (ZEI) at http://www.zei.de/download/Phare/data.pdf

${ }^{12}$ See Devereux et al, 1999.

${ }^{13}$ GTAP is the Global Trade Analysis Project, based in Purdue, Illinois.

${ }^{14}$ Food crops, animal products, minerals, food products, light manufacturing, heavy manufacturing, textiles, metals, services.

${ }^{15}$ UK, France, Germany, Italy, Spain, Netherlands, Belgium, Portugal, Greece, Denmark, Sweden, Finland, Austria, Ireland, Poland, Czech Rep, Hungary, Other European Union, Other Western Europe, South-East European Countries, Turkey, CIS, USA, Canada, Mexico, Brazil, Argentina, Chile, Other Latin America, South Africa, OtherAfrica, Middle East and North Africa, India, South Asia, South-East Asia, East Asia, Japan, China, Australia/New Zealand.
} 
(smaller NAFTA country), Japan (large non-EU, non-NAFTA country), Turkey (EU accession candidate), India and China (large, formerly closed, now opening up fast to trade). The scores and rankings of these 8 countries in the 2001 Warwick Index for Economic Globalisation are as follows: 
Table 2: Warwick Economic Globalisation scores for selected countries, 2001.

\begin{tabular}{||lll||}
\hline \hline Country & Score & Ranking \\
\hline UK & 0.272 & 15 \\
\hline Belgium & 0.664 & 2 \\
\hline Ireland & 0.779 & 1 \\
USA & 0.210 & 58 \\
Canada & 0.240 & 32 \\
Japan & 0.184 & 93 \\
Turkey & n.a & $\mathrm{n} / \mathrm{a}$ \\
India & 0.214 & 49 \\
China & 0.244 & 30 \\
\hline \hline
\end{tabular}

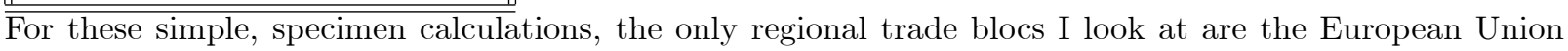
(15 members as of 2001, to which Ireland, Belgium and the UK belonged) and NAFTA (to which Canada and the USA belonged).

The tables in the Appendix show the estimated Gini coefficients for equality of market access in imports for our 8 selected countries for each of the 9 industries. In each case, I calculate 3 Ginis: the Global-Based Gini, $G G$, the Regional-Based Gini, $H R B G$, (which only differs from the former for those countries which are members of the EU or NAFTA) and a third Gini calculating using a Home-Rest of World split, $H B G$.

Taking crude arithmetic averages across our 8 specimen countries, the average Gini coefficients by industry are as follows: 
Table 3: Gini coefficients - average by industry

\begin{tabular}{||llll||}
\hline \hline Industry & Home/Foreign & Home/Regional & Global \\
& $H B G$ & $H R B G$ & $G G$ \\
Food crops & 0.66 & 0.76 & 0.87 \\
Meat/dairy & 0.85 & 0.88 & 0.93 \\
Minerals & 0.47 & 0.52 & 0.84 \\
Food Prods & 0.78 & 0.84 & 0.90 \\
Lt Man & 0.49 & 0.57 & 0.73 \\
Hvy man & 0.46 & 0.58 & 0.70 \\
Textiles & 0.47 & 0.57 & 0.75 \\
Metals & 0.62 & 0.70 & 0.82 \\
Services & 0.87 & 0.88 & 0.90 \\
\hline
\end{tabular}

The meat and dairy sector is the least globalised sector (on all measures), partly reflecting protectionism, partly the effect of sanitary and phytosanitary standards and partly transport costs. Food products follow for similar reasons. Services and food crops are also relatively low in terms of equality of market access. At the other extreme, minerals are probably the most open sector on the first two measures (though interestingly, not on the Global Gini), while textiles (even despite the multi-fibre agreements) and light and heavy manufacturing were relatively open.

Comparing different countries, in table 4 I have calculated the crude averages of sectoral Gini coefficients including and excluding minerals. 
Table 4a: overall average Gini scores across all sectors

\begin{tabular}{|llll||}
\hline \hline Overall & Home/Foreign & Home/Regional & Global \\
& $H B G$ & $H R B G$ & $G G$ \\
UK & 0.67 & 0.75 & 0.84 \\
Belgium & 0.39 & 0.58 & 0.77 \\
Ireland & 0.47 & 0.70 & 0.84 \\
USA & 0.62 & 0.65 & 0.69 \\
Canada & 0.68 & 0.79 & 0.84 \\
Japan & 0.70 & 0.70 & 0.83 \\
Turkey & 0.55 & 0.55 & 0.86 \\
India & 0.77 & 0.77 & 0.91 \\
China & 0.81 & 0.81 & 0.85 \\
\hline \hline
\end{tabular}

Table 4b: overall average Gini scores excluding minerals

\begin{tabular}{|llll||}
\hline \hline Excluding Minerals & Home/Foreign & Home/Regional & Global \\
& $H B G$ & $H R B G$ & $G G$ \\
UK & 0.67 & 0.76 & 0.83 \\
Belgium & 0.44 & 0.64 & 0.77 \\
USeland & 0.51 & 0.74 & 0.84 \\
Canada & 0.64 & 0.66 & 0.69 \\
Japan & 0.68 & 0.79 & 0.84 \\
Turkey & 0.69 & 0.69 & 0.83 \\
India & 0.60 & 0.60 & 0.86 \\
China & 0.80 & 0.80 & 0.90 \\
\hline \hline
\end{tabular}

Perhaps the most important insight from a first look at Tables $4 a-b$ is that, while Belgium and Ireland might appear to be offering by far the easiest access to their markets for foreigners (as shown in the first column), this foreign access is in fact dominated by other EU producers. 'Corrected' for the role of regional 


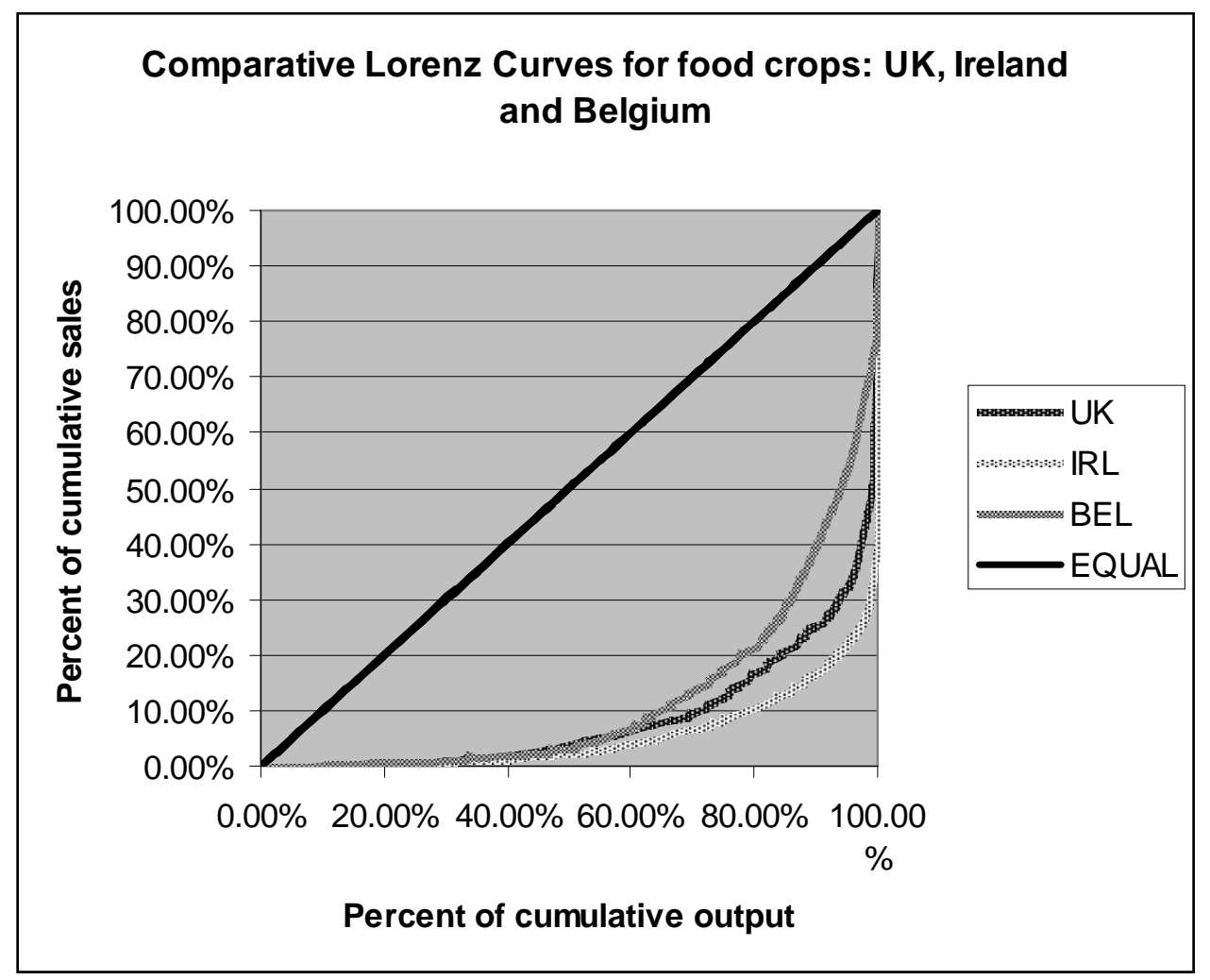

producers, Belgium is only marginally more equal in the access it gives than the USA, while Ireland is distinctly average in our group of countries. This effect can be seen in Figure 2, below, which shows the Lorenz curves for the UK, Ireland and Belgium in the case of food crops. In fact, Ireland's consumption in this sector is even more heavily concentrated than that of the UK, as seen by the fact that its curve lies below the other two. This reflects the effects not just of home and regional bias, but of the domination of the UK in Ireland's intra-regional trade.

A comparison of country rankings, based on a crude average of sectoral Ginis is quite informative here. The Home/Foreign Ginis, which ignore regionalism, agree with the Warwick rankings in placing Belgium and Ireland at 1 and 2 (compared to 2 and 1 respectively in te Warwick table), but the USA appears far more globalised on our measure (ranked 4th instead of 6th, and ahead of the UK and Canada). Once 'correction' is made for the impact of regional trade, the USA, in fact, overtakes Ireland to be the third most globalised economy (Turkey being the most globalised) of the 8. Indeed, the Global Gini, taking account also of uneven distributions of trade within the Region and within the rest of the World, actually show the USA as the most 
globalised of our specimen economies. Ireland, by contrast, trades very heavily with the UK, and its apparent openness in terms of trade share of GDP is to some degree a statistical illusion. At the other end of the table, our measures agree with the conclusions of the Warwick study regarding Japan and India. The calculations do not really uphold the Warwick picture of China as a globalised economy - it really only ranks ahead of India on Global trade in our sample.

Table 5: A comparison of country rankings

\begin{tabular}{|c|c|c|c|c|}
\hline Rankings & Warwick & $\begin{array}{l}\text { Home/Foreign Ginis } \\
H B G\end{array}$ & $\begin{array}{l}\text { With regional } \\
H R B G\end{array}$ & $\begin{array}{l}\text { Global } \\
G G\end{array}$ \\
\hline UK & 3 & 5 & 5 & $3=$ \\
\hline Belgium & 2 & 1 & 2 & 2 \\
\hline Ireland & 1 & 2 & 4 & $5=$ \\
\hline USA & 7 & 4 & 3 & 1 \\
\hline Canada & 5 & 6 & 7 & $5=$ \\
\hline Japan & 8 & 7 & 6 & $3=$ \\
\hline Turkey & na & 3 & 1 & $7=$ \\
\hline India & 6 & 8 & 8 & 9 \\
\hline China & 4 & 9 & 9 & $7=$ \\
\hline
\end{tabular}

\section{$7 \quad$ Further Issues}

The results above may require some further refinement: for example, more sophisticated treatment of regionalism (to take account of looser trade bloc association and the like). This may require a multi-layer breakdown of regions.

A word of caution is needed in the 'equality of access' interpretation of the Gini coefficients. If a large, foreign producer has a very sheltered market, due either to protectionism or to transport costs, its own production may be large but little may be exported (as it is uncompetitive). This would reduce the calculated Gini coefficients for trade for all other countries. In principle, it might be worth exploring ways to correct for 
this, although this would reduce the simplicity of the Gini approach. ${ }^{16}$

There is an issue over the treatment of very large countries. In particular, in this study, the United States economy is being treated as a unit in the calculations. In practice, it may well be that results might be altered by splitting it into subregions, so that, for example, Californian producers would be expected to have less access to New York markets than New York or New Jersey producers. The precise effect this would have on 'equality of access' measures would probably require some further data analysis and simulation work.

The link between Gini coefficients and regression analysis (as outlined, for example, in the Ogwang, 2000, paper) may also be a fruitful route for investigation. In particular, it may well be possible to derive Gini coefficients from a variety of 'theoretical gravity' equations, with and without distance effects, regional effects, tariffs and the like, and in this way to decompose the 'causes' of global and regional integration and their changes over time.

\section{References}

[1] Anderson, J.E. and E.Van Wincoop (2003): 'Gravity with Gravitas: a Solution to the Border Puzzle.' American Economic Review, March 2003, 93, 170-192.

[2] Atkinson, A.B. (1983): 'The Economics of Inequality', Oxford, Clarendon, 1983.

[3] Baldwin, R.E. and A.J. Venables (1995): 'Regional Economic Integration.' In Gene M. Grossman and Kenneth Rogoff (eds) Handbook of International Economics, Vol. 3. pp 1597-1644, Elsevier, Amsterdam.

[4] Bergstrand, J.H. (1989): 'The Generalised Gravity Equation, Monopolistic Competition and the FactorProportions Theory of International Trade', Review of Economics and Statistics 71 pp 143-153.

[5] Brenton, P., J.Sheehy and M.Vancauteren (2001): 'Technical Barriers to Trade in the EU: Data, Trends and Implications for Accession Countries'. Journal of Common Market Studies, 39, 241-260.

\footnotetext{
${ }^{16}$ A quite different, though interesting approach to measuring globalisation is by Riezman et al (2005). This uses general equilibrium simulations to compare a country's actual economic structure with a counterfactual simulation of how it might be if trade were completely liberalised. Clearly, this is a much more model-based approach, and does have some sensitivity to the model structure and elasticities used. However, interestingly, Riezman et al agree with the calculations here that the USA is a relatively globalised economy (second out of a sample of eight OECD countries), which is at odds with the Warwick indices.
} 
[6] Centre for the Study of Globalisation and Regionalisation, Warwick (2005): 'Globalisation Index'. http://www2.warwick.ac.uk/fac/soc/csgr/index/

[7] Deardorff, A. (1984): 'Testing trade theories and predicting trade flows' in : R. W. Jones \& P. B. Kenen (ed.) 'Handbook of International Economics', chapter 10, pages 467-517, Elsevier,1984.

[8] Deardorff, A. (1998): 'Determinants of Bilateral Trade: Does Gravity Work in a Neoclassical World?' in J.A.Frankel (ed): The Regionalisation of the World Economy, University of Chicago Press.

[9] Devereux, M., Griffith, R. and Simpson, H. (2004): 'The geographic distribution of production activity in the UK', Regional Science and Urban Economics, v. 34, iss. 5. 533-64, September 2004.

[10] Dixit, A., and Stiglitz, J.E. (1977): 'Monopolistic Competition and Optimum Product Diversity.' American Economic Review, 67, pp 297-308.

[11] Edwards, T.H. (2005): 'Implicit Trade Costs and the European Single Market'. Loughborough Economics Discussion Paper ERP05-04, May 2005.

[12] Hillberry, R.(1999): 'Explaining the Border Effect: What Can We Learn from Disaggregated Commodity Flow Data'. Indiana University Graduate Students Economics Working Paper Series 9802.

[13] Kearney, A.T. (2003): 'Foreign Policy Magazine Globalization Index'. http://www.atkearney.com/shared_res/pdf/Measuring_Globalization_S.pdf

[14] Krugman, P. (1979): 'Increasing Returns, Monopolistic Competition and International Trade'; Journal of International Economics, 9: 469-79.

[15] Krugman, P.R. (1991): 'Geography and Trade.' Leuven University Press, Belgium.

[16] Lockwood, B. (2004): 'How Robust is the Foreign Policy/Kearney Globalisation Index?': The World Economy, Volume 27 Page 507 - April 2004.

[17] Lockwood, B. and Michela Redoano, (2005), 'The CSGR Globalisation Index: an Introductory Guide', Centre for the Study of Globalisation and Regionalisation Working Paper 155/04, Warwick, UK. 
[18] McCallum, J. (1995): 'National Borders Matter: Canada-US Regional Trade Patterns.' American Economic Review, 85: 615-23.

[19] Ogwang, T. (2000): 'A Convenient Method of Computing the Gini Index and its Standard Error': Oxford Bulletin of Economics and Statistics, 62, 1, 2000.

[20] Riezman, R., J.Whalley and S.Zhang (2005): 'Metrics capturing the degree to which individual countries are globalized', CESinfo working paper 1450, April 2005.

[21] Trefler, D. (1995): 'The Case of the Missing Trade and Other Mysteries.' American Economic Review 85 (Dec 1995): 1029-1046. 


\section{Appendix 1: Summary tables of Gini coefficients for the 9 speci- men countries.}

\begin{tabular}{||llll||}
\hline : Food crops & & & \\
\hline \hline Food Crops & $H B G$ & $H R B G$ & $G G$ \\
UK & 0.47 & 0.66 & 0.82 \\
Belgium & 0.22 & 0.46 & 0.76 \\
Ireland & 0.55 & 0.77 & 0.89 \\
USA & 0.74 & 0.78 & 0.85 \\
Canada & 0.56 & 0.80 & 0.88 \\
Japan & 0.82 & 0.82 & 0.90 \\
Turkey & 0.82 & 0.82 & 0.93 \\
India & 0.92 & 0.92 & 0.98 \\
China & 0.80 & 0.80 & 0.82 \\
\hline \hline
\end{tabular}

b: Meat and Dairy

\begin{tabular}{|llll||}
\hline \hline Meat and Dairy & $H R G$ & $H R B G$ & $G G$ \\
UK & 0.88 & 0.91 & 0.95 \\
Belgium & 0.81 & 0.89 & 0.95 \\
Ireland & 0.92 & 0.96 & 0.98 \\
USA & 0.76 & 0.78 & 0.79 \\
Canada & 0.90 & 0.93 & 0.96 \\
Japan & 0.90 & 0.90 & 0.95 \\
Turkey & 0.72 & 0.72 & 0.92 \\
India & 0.93 & 0.93 & 0.99 \\
China & 0.86 & 0.86 & 0.87 \\
\hline \hline
\end{tabular}


c: Minerals

\begin{tabular}{|llll||}
\hline \hline Minerals & $H B G$ & $H R B G$ & $G G$ \\
UK & 0.65 & 0.66 & 0.90 \\
Belgium & 0.02 & 0.08 & 0.72 \\
Ireland & 0.08 & 0.38 & 0.87 \\
USA & 0.46 & 0.55 & 0.69 \\
Canada & 0.73 & 0.75 & 0.88 \\
Japan & 0.80 & 0.80 & 0.82 \\
Turkey & 0.15 & 0.15 & 0.86 \\
India & 0.54 & 0.54 & 0.96 \\
China & 0.77 & 0.77 & 0.84 \\
\hline \hline
\end{tabular}

d: Food products

\begin{tabular}{|llll||}
\hline \hline Food Products & $H B G$ & $H R B G$ & $G G$ \\
UK & 0.82 & 0.88 & 0.91 \\
Belgium & 0.59 & 0.81 & 0.90 \\
Ireland & 0.66 & 0.86 & 0.92 \\
USA & 0.72 & 0.73 & 0.74 \\
Canada & 0.82 & 0.87 & 0.90 \\
Japan & 0.75 & 0.75 & 0.88 \\
Turkey & 0.86 & 0.86 & 0.96 \\
India & 0.93 & 0.93 & 0.98 \\
China & 0.91 & 0.91 & 0.92 \\
\hline \hline
\end{tabular}


e: Light manufactures

\begin{tabular}{|llll||}
\hline \hline Light Manufactures & $H B G$ & $H R B G$ & $G G$ \\
UK & 0.55 & 0.64 & 0.72 \\
Belgium & 0.24 & 0.44 & 0.62 \\
Ireland & 0.17 & 0.44 & 0.67 \\
USA & 0.52 & 0.56 & 0.61 \\
Canada & 0.60 & 0.74 & 0.78 \\
Japan & 0.61 & 0.61 & 0.80 \\
Turkey & 0.30 & 0.30 & 0.73 \\
India & 0.69 & 0.69 & 0.83 \\
China & 0.69 & 0.69 & 0.80 \\
\hline \hline
\end{tabular}

\section{f: Heavy manufactures}

\begin{tabular}{|llll||}
\hline \hline Heavy Manufactures & $H B G$ & $H R B G$ & $G G$ \\
UK & 0.56 & 0.70 & 0.74 \\
Ireland & 0.16 & 0.54 & 0.62 \\
USA & 0.41 & 0.63 & 0.73 \\
Canada & 0.53 & 0.57 & 0.59 \\
Japan & 0.38 & 0.65 & 0.68 \\
Turkey & 0.49 & 0.49 & 0.65 \\
India & 0.33 & 0.33 & 0.76 \\
China & 0.50 & 0.50 & 0.71 \\
\hline \hline
\end{tabular}




\begin{tabular}{||llll||} 
g) Textiles & & & \\
\hline \hline Textiles & $H B G$ & $H R B G$ & $G G$ \\
UK & 0.51 & 0.62 & 0.77 \\
Belgium & 0.18 & 0.42 & 0.62 \\
Ireland & 0.15 & 0.62 & 0.78 \\
USA & 0.53 & 0.55 & 0.64 \\
Canada & 0.57 & 0.62 & 0.71 \\
Japan & 0.55 & 0.55 & 0.77 \\
Turkey & 0.31 & 0.31 & 0.78 \\
India & 0.73 & 0.73 & 0.87 \\
China & 0.70 & 0.70 & 0.77 \\
\hline \hline
\end{tabular}

h: Metals

\begin{tabular}{||llll||}
\hline \hline Metals & $H B G$ & $H R B G$ & $G G$ \\
UK & 0.70 & 0.75 & 0.82 \\
Belgium & 0.45 & 0.69 & 0.80 \\
Ireland & 0.47 & 0.78 & 0.88 \\
USA & 0.66 & 0.68 & 0.70 \\
Canada & 0.65 & 0.79 & 0.82 \\
Japan & 0.47 & 0.47 & 0.74 \\
Turkey & 0.54 & 0.54 & 0.89 \\
India & 0.79 & 0.79 & 0.91 \\
China & 0.81 & 0.81 & 0.86 \\
\hline \hline
\end{tabular}




\begin{tabular}{l|lll||} 
i) Services & & & \\
\hline \hline Services & $H B G$ & $H R B G$ & $G G$ \\
UK & 0.90 & 0.91 & 0.92 \\
Belgium & 0.86 & 0.89 & 0.91 \\
Ireland & 0.78 & 0.82 & 0.87 \\
USA & 0.63 & 0.63 & 0.63 \\
Canada & 0.93 & 0.94 & 0.95 \\
Japan & 0.91 & 0.91 & 0.93 \\
Turkey & 0.91 & 0.91 & 0.94 \\
India & 0.94 & 0.94 & 0.96 \\
China & 0.93 & 0.93 & 0.96 \\
\hline \hline
\end{tabular}




\section{Appendix 2: Derivation of the Gini coefficient in terms of trade}

\section{costs.}

Consider a situation where $P_{c}=1$ and $T_{c}=1$ for all $c$. We have shown in the main paper that

$$
x_{c, c c}=\left(1-\phi_{c, c c}\right)^{(\sigma-1)} y_{c} X_{c c} \pi_{c c}^{\sigma-1}
$$

and since

$$
\sum_{c} x_{c, c c}=X_{c c}
$$

it follows that

$$
X_{c c}=\left(1-\phi_{c, c c}\right)^{(\sigma-1)} y_{c} X_{c c} \pi_{c c}^{\sigma-1}
$$

Expressions can be found for the price index in country cc, $\pi_{c c}$, and a value for what it would equal if there were no trade costs, $\pi *_{c c}$ :

$$
\begin{aligned}
& \pi_{c c}=\left(\sum_{c}\left(1-\phi_{c, c c}\right)^{(\sigma-1)} y_{c}\right)^{1 / 1-\sigma} ; \\
& \pi_{c c}^{*}=\left(\sum_{c} y_{c}\right)^{1 / 1-\sigma}=Y^{1 / 1-\sigma} .
\end{aligned}
$$

Noting that

$$
x_{c, c c} / y_{c} X_{c c}=\left(1-\phi_{c, c c}\right)^{(\sigma-1)} \pi_{c c}^{\sigma-1}
$$

we can substitute into the formula for the Global Gini:

$$
\begin{aligned}
G G_{c c} & =\left(\sum_{c} \sum_{d} y_{c} y_{d} \sqrt{\left(\left(x_{c, c c} / y_{c}\right)-\left(x_{d, c c} / y_{d}\right)\right)^{2}}\right) / X_{c c} Y, \\
& =\left(\sum_{c} \sum_{d} y_{c} y_{d} \sqrt{\left(\left(1-\phi_{c, c c}\right)^{(\sigma-1)}-\left(1-\phi_{d, c c}\right)^{(\sigma-1)}\right)^{2}}\right)\left(\pi_{c c} / \pi_{c c}^{*}\right)^{\sigma-1} ; \\
& =\left(\sum_{c} \sum_{d} y_{c} y_{d} \sqrt{\left(\left(1-\phi_{c, c c}\right)^{(\sigma-1)}-\left(1-\phi_{d, c c}\right)^{(\sigma-1)}\right)^{2}}\right)\left(Y /\left(\sum_{c}\left(1-\phi_{c, c c}\right)^{(\sigma-1)} y_{c}\right)\right) .
\end{aligned}
$$




\section{CSGR Working Paper}

180/05 November

181/05 November

182/05 November

183/05 December

184/05 December

185/05 December

186/05 December

187/06 January

188/06, January

189/06, January

190/06, January

191/06, January

192.06, January

193/06 February

194/06 February

195/06 March

196/06 March

197/06 March
Ariel Buira

The Bretton Woods Institutions: Governance without Legitimacy?

Jan-Erik Lane

International Organisation Analysed with the Power Index Method.

Claudia M. Fabbri

The Constructivist Promise and Regional Integration: An Answer to 'Old' and 'New' Puzzles: The South American Case.

Heribert Dieter

Bilateral Trade Afreements in the Asia-Pacific: Wise or Foolish Policies?

Gero Erdmann

Hesitant Bedfellows: The German Stiftungen and Party Aid in Africa. Attempt at an Assessment

Nicola Maaser and Stefan Napel

Equal Representation in Two-tier Voting Systems

Gianluca Grimalda

Can Labour Market Rigidity Lead to Economic Efficiency? The Technological Change Link

Leonardo Ramos

Collective political agency in the XXIst century: Civil society in an age of globalization

Mustafizur Rahman and Wasel Bin Shadat

NAMA Negotiations in the WTO and Preference Erosion: Concerns of Bangladesh and Other Regional LDCs

Amrita Dhillon, Javier Garcia-Fronti, Sayantan Ghosal and Marcus Miller

Bargaining and Sustainability: The Argentine Debt Swap

Marcus Miller, Javier Garcia-Fronti and Lei Zhang

Contractionary devaluation and credit crunch: Analysing Argentina.

Wyn Grant

Why It Won’t Be Like This All The Time: the Shift from Duopoly to Oligopoly in Agricultural Trade

Michael Keating

Global best practice(s) and electricity sector reform in Uganda

Natalie Chen, Paola Conconi and Carlo Perroni

Does migration empower married women?

Emanuel Kohlscheen

Why are there serial defaulters? Quasi-experimental evidence from constitutions.

Torsten Strulik

Knowledge politics in the field of global finance? The emergence of a cognitive approach in banking supervision

Mark Beeson and Hidetaka Yoshimatsu

Asia’s Odd Men Out: Australia, Japan, and the Politics of Regionalism

Javier Garcia Fronti and Lei Zhang

Political Instability and the Peso Problem 
198/06 March

199/06 March

200/06 April

201/06 April

202/06 April

203/06 April

204/06 April

205/06 April

206/06 May
Hidetaka YOSHIMATSU

Collective Action Problems and Regional Integration in ASEAN

Eddy Lee and Marco Vivarelli

The Social Impact of Globalisation in the Developing Countries.

Jan Aart Scholte

Political Parties and Global Democracy

Peter Newell

Civil society participation in trade policy-making in Latin America: The Case of the Environmental Movement

Marcus Miller and Dania Thomas

Sovereign Debt Restructuring: The Judge, the Vultures and Creditor Rights

Fondo Sikod

Globalisation and Rural Development in Africa: The Case of the Chad-Cameroon Oil Pipeline.

Gilles Quentel

The Translation of a Crucial Political Speech: G.W.Bush' State of the Union Address 2003 in Le Monde

Paola Robotti

Arbitrage and Short Selling: A Political Economy Approach

T.Huw Edwards

Measuring Global and Regional Trade Integration in terms of Concentration of Access

\section{Centre for the Study of Globalisation and Regionalisation}

University of Warwick

Coventry CV4 7AL, UK

Tel: +44 (0)24 76572533

Fax: +44 (0)24 76572548

Email: csgr@warwick.ac.uk

Web address: http://www.csgr.org 